\title{
Exploring the Principal Factors Influencing IPOs in the Emerging Growth Enterprise Market of China
}

\author{
Hai Long
}

\begin{abstract}
A successful IPO is determined by many different factors across listing markets. Identifying the principal factors and satisfying with them are prerequisites for an IPO firm. The purpose of this study is through Principal Factor Analysis (PFA) to investigate these determinants in the emerging Growth Enterprise Market of China. Based on a sample of the initial 243 IPOs in the market over 2009-2011 period, this study shows the five factors - firms size, profitability, growth rate, IPO volume, and dividend rate are the most significant factors for a successful IPO in the market.
\end{abstract}

Index Terms-Entrepreneurial firms, growth enterprise market of china, IPO determinants, principal factor analysis.

\section{INTRODUCTION}

An IPO decision is affected by various macro-determinants, such as country-related determinants [1], [2], exchange-based determinants [3], and firm-specific ones [4]. The principal factors influcing an IPO approval vary due to these macro-determinants [5]. In terms of the firm-specific determinants, there are many micro-factors impacting on the IPO likelihood widely across IPO markets, such as revenue, profit, profit rate, potential growth, fundraising amount, net asset, returns on asset, etc. This paper aims to detect what the principal factors are for an IPO in the Growth Enterprise Market of China (GEMC). The Principal Factor Analysis (PFA) is adopted for this study through software SPSS. PFA as a branch of modern statistics is initially developed by Charles Spearman in 1904, which, via investigating the matrix of correlation coefficient between multivariates, identifies and extracts the most representative factors with the typical characteristics of all related variables.

Although IPOs have been extensively discussed based on a wide variety of listing markets, very little of literature sheds light on that in the GEMC - an emerging listing venue launched in 2009, which is designed for entrepreneurial companies in China. This study bridges this gap to help these firms identify these significant IPO factors, in an effort to achieve a successful IPO in the new listing market.

\section{BACKGROUND OF THE GEMC}

The purpose of establishing the GEMC is not only diversifying Chinese capital market, but also addressing the

Manuscript received September 9, 2013; revised October 15, 2013.

H. Long is with the School of Business, Edith Cowan University, Perth, 6027 Australia (e-mail: soholonghai@163.com). long-standing financing difficulties for the Small and Medium-sized Enterprises (SMEs) in China. The SMEs act as a pivotal role in terms of boosting economy, creating employment opportunities, advancing innovations in China. By the end of 2011, Chinese SMEs have contributed to approximately 50\% national tax revenue, 60\% GDP, $80 \%$ job opportunities, $65 \%$ patents and intellectual properties (the data was collected from the Ministry of Industry and Information Technology of China).

Chinese SEMs have been confronting financing difficulties for years [6]. According a survey conducted by the largest E-business company Alibaba and the National Development Centre of Peking University in 2011, 78\% SMEs have experienced or are experiencing money shortage in Zhejiang - a SMEs dominated state. Additionally, 50\% owners of the SMEs raised fund through loaning from relatives and friends, and other informal channels. They have no access to bank loan because of their high loan default rate and low credit rate [7]. Due to the SMEs' contribution to Chinese economy, the central government is keen to broaden financing channels for SMEs and to bridge the financing gap. Under this circumstances, the GEMC was established, because IPO markets are able to provide SMEs with an efficient plateform for raising capital, and reduce their financing cost greater than other channels [8].

The GEMC was inaugurated in Shenzhen Stock Market on $30^{\text {th }}$ October 2009 with 28 initial IPO companies. This market not only facilitates capital-raising for those growing SMEs that have high profitability, technology innovation and advanced business models, it also facilitates venture capitalists exiting from these investee companies. According to the latest record of the GEMC official website, by 10 September 2012 there have been 355 listed companies with total market capitalization at RMB $¥ 924,877,099,614$ and total amount of issued shares $58,572,665,181$. Amost half of these firms was backed by venture capitalists.

\section{THEORETICAL FRAMEWORK}

Assuming there are $n$ variables $X=\left(X_{1}, X_{2}, X_{3}, \cdots X_{n}\right)$, which stand for IPO firms here; the principal factors $F=\left(F_{1}\right.$, $\left.F_{2}, F_{3} \cdots F_{m}, m<n\right)$, which are proxies of IPO determinants, so a factor model may be built as below:

$$
\left\{\begin{array}{c}
X_{1}=\lambda_{11} F_{1}+\lambda_{12} F_{2}+\cdots+\lambda_{1 m} F_{m}+\varepsilon_{1} \\
X_{2}=\lambda_{21} F_{1}+\lambda_{22} F_{2}+\cdots+\lambda_{2 m} F_{m}+\varepsilon_{2} \\
\vdots \\
X_{n}=\lambda_{n 1} F_{1}+\lambda_{n 2} F_{2}+\cdots+\lambda_{n m} F_{m}+\varepsilon_{n}
\end{array}\right.
$$


where, $\lambda_{n m}$ is called factor loading, which actually is the coefficient of correlation between $\mathrm{F}$ and $\mathrm{X}$, greater the absolute value is, stronger the relation; $\varepsilon$ is an external disturbance, which can beingored in most.

Once the results for $\mathrm{F}$ are given by software SPSS, the principal variables are accordingly identified. Subsequently, each factor score for these principal factor $F$ may be calculated through a regression model:

so

$$
\begin{gathered}
F_{1}=\beta_{11} X_{1}+\beta_{12} X_{2}+\cdots \beta_{1 n} X_{n} \\
F_{2}=\beta_{21} X_{1}+\beta_{22} X_{2}+\cdots \beta_{2 n} X_{n} \\
\vdots \\
F_{m}=\beta_{m 1} X_{1}+\beta_{m 2} X_{2}+\cdots \beta_{m n} X_{n}
\end{gathered}
$$

$$
I P O=F\left(F_{1} \cdots F_{m}\right) .
$$

\section{DATA}

According to the listing procedures of China's stock market, IPO firms have to apply for an IPO permission from the China Securities Regulatory Commission (CSRC), and they have to specify their IPO-specific information in their IPO prospectus. The CSRC publishes those documents on its website (www. csrc.com) for public investor's reference. The data used for this study was collected from these IPO prospectuses of listing applicants. From September 2009 to December 2011, the CSRC reviwed 243 IPO applications. In particular, 205 of which were approved, 37 of them were rejected, but the data on about 233 of IPO cases has been collected.

The data includes components: net profit and income in the last three years before IPOs $\left(\mathrm{NP}_{3}, \mathrm{NP}_{2} \mathrm{NP}_{1}, \mathrm{IN}_{3}, \mathrm{IN}_{2}\right.$, $\left.\mathrm{IN}_{3}\right)$, growth rate of NP and IN in the last two years $\left(\mathrm{GRN}_{2}\right.$, $\left.\mathrm{GRN}_{1}, \mathrm{GRI}_{2}, \mathrm{GRI}_{1}\right)$, profit rate in the last two years $\left(\mathrm{PR}_{2}\right.$, $\mathrm{PR}_{1}$ ), share amount issued ( $\mathrm{SAI}$ ), earning rate per share (EPS), price earning rate (PE), net assets in the last year (NA), Net Profit per share in the last year (NS), return rate on equity in the last year (ROE), IPO volume (IV), accumulated dividend amount in the last three years (DA), average dividend rate in the three years (DR).

\section{EMPIRICAL ANALYSIS}

There are around 21 IPO-related financial determiants directly or indirectly impacting on the IPO likelihood in the GEMC. Some of them are very significant, but some are not. After putting the data into the PFA module in SPSS, the below results are received.

TABLE I: KMO AND BARTLETT'S TEST

\begin{tabular}{llr}
\hline Kaiser-Meyer-Olkin Measure of Sampling Adequacy (KMO). & 0.77 \\
Bartlett's Test of Sphericity & Approx. Chi-Square & 0.98 \\
& df & 210 \\
& Sig. & .000 \\
\hline
\end{tabular}

$$
K M O=\frac{\sum \sum_{i \neq j} r_{i j}^{2}}{\sum \sum_{i \neq j} r_{i j}^{2}+\sum \sum_{i \neq j} a_{i j}^{2}} \quad(0>\mathrm{KMO}>1)
$$

$r_{i j}$ is the coefficient of correlation between variable $i$ and $j$; $a_{i j}$ is the coefficient of partial correlation between variable $i$ and $j$.

As the formula indicated, the KMO and Bartlett's Test is to examine the PFA applicability through investigating the partial correlation between variables. Usually, when the $\mathrm{KMO}$ value is great over 0.6, it means PFA is applicable. Closer to 1 , it means more significant to do this test. If the

\begin{tabular}{|c|c|c|}
\hline & Initial & Extraction \\
\hline IN3 & 1.000 & 0.984 \\
\hline IN2 & 1.000 & 0.988 \\
\hline IN1 & 1.000 & 0.992 \\
\hline $\mathrm{GRI}_{2}$ & 1.000 & 0.841 \\
\hline $\mathrm{GRI}_{1}$ & 1.000 & 0.576 \\
\hline NP3 & 1.000 & 0.945 \\
\hline NP2 & 1.000 & 0.989 \\
\hline NP1 & 1.000 & 0.997 \\
\hline $\mathrm{GRN}_{2}$ & 1.000 & 0.838 \\
\hline $\mathrm{GRN}_{1}$ & 1.000 & 0.737 \\
\hline $\mathrm{PR}_{2}$ & 1.000 & 0.948 \\
\hline $\mathrm{PR}_{1}$ & 1.000 & 0.905 \\
\hline SAI & 1.000 & 0.841 \\
\hline EPS & 1.000 & 0.992 \\
\hline P.E. & 1.000 & 0.560 \\
\hline NA & 1.000 & 0.988 \\
\hline NS & 1.000 & 0.986 \\
\hline ROE & 1.000 & 0.349 \\
\hline IV & 1.000 & 0.849 \\
\hline DA & 1.000 & 0.965 \\
\hline DR & 1.000 & 0.884 \\
\hline
\end{tabular}
value is under 0.5 , the PFA is infeasible.

As the table illustrated, the $\mathrm{KMO}=0.771$ at a significant level 0, so the PFA should be applicable and the analysis result are expected to be acceptable.

According to PFA model $X_{n}=\lambda_{n 1} F_{1}+\lambda_{n 2} F_{2}+\ldots \lambda_{n m} F_{m}$, it may be denoted by matrix format $X=A F$. The sum of squares of the components, which are in the $\mathrm{n}$ row of the matrix $A$, is the communalities, denoted by formula $h_{n}^{2}=\sum_{m=1}^{k} \lambda_{n m}^{2}$. It demonstrates the degree of the variable $x$ characteristics which can be described by the extracted principal factors $\mathrm{F}$. The coefficient $h 2_{n}$ tends to 1 , which means the principal factors are able to interpret the most information of variable $x$.

This Communalities table indicates the extent of the original information that can be extracted from each variable. Except the variable PE, the extraction levels of the rest variables are over 0.5 , so the potential principal factors that will be extracted have a comprehensive representative for these nominated variables. It means the extracted facors have significant contribution to IPO approval. Another striking feature is the greatest variables over 0.9 are all profit-related, hence, the proposed variable (NP) is expected to be extracted as the most significant factors. 
TABLE III: TOTAL VARIANCE EXPLAINED

\begin{tabular}{|c|c|c|c|c|c|c|c|c|c|}
\hline \multirow[b]{2}{*}{ Comp. } & \multicolumn{3}{|c|}{ Initial Eigenvalues } & \multicolumn{3}{|c|}{$\begin{array}{l}\text { Extraction Sums of } \\
\text { Squared Loadings }\end{array}$} & \multicolumn{3}{|c|}{$\begin{array}{c}\text { Rotation Sums of Squared } \\
\text { Loadings }\end{array}$} \\
\hline & $\begin{array}{c}\text { Total } \\
(\lambda)\end{array}$ & $\begin{array}{l}\% \text { of } \\
\text { Var }\end{array}$ & $\begin{array}{l}\text { Cumulati } \\
\text { ve } \%\end{array}$ & $\begin{array}{c}\text { Total } \\
(\lambda)\end{array}$ & $\begin{array}{l}\% \text { of } \\
\text { Var }\end{array}$ & $\begin{array}{l}\text { Cumulati } \\
\text { ve } \%\end{array}$ & $\begin{array}{c}\text { Total } \\
(\lambda)\end{array}$ & $\begin{array}{l}\% \text { of } \\
\text { Var }\end{array}$ & $\begin{array}{l}\text { Cumulati } \\
\text { ve } \%\end{array}$ \\
\hline 1 & 9.68 & 46.09 & 46.09 & 9.68 & 46.09 & 46.09 & 9.64 & 45.90 & 45.90 \\
\hline 2 & 2.60 & 12.39 & 58.48 & 2.60 & 12.39 & 58.48 & 2.04 & 9.70 & 55.60 \\
\hline 3 & 1.81 & 8.60 & 67.08 & 1.81 & 8.60 & 67.08 & 1.95 & 9.28 & 64.89 \\
\hline 4 & 1.60 & 7.62 & 74.70 & 1.60 & 7.62 & 74.70 & 1.77 & 8.44 & 73.33 \\
\hline 5 & 1.46 & 6.96 & 81.65 & 1.46 & 6.96 & 81.65 & 1.64 & 7.80 & 81.13 \\
\hline 6 & 1.01 & 4.80 & 86.45 & 1.01 & 4.80 & 86.45 & 1.12 & 5.33 & 86.45 \\
\hline 7 & 0.84 & 4.00 & 90.45 & & & & & & \\
\hline 8 & 0.71 & 3.38 & 93.84 & & & & & & \\
\hline 9 & 0.56 & 2.66 & 96.50 & & & & & & \\
\hline 10 & 0.32 & 1.52 & 98.02 & & & & & & \\
\hline 11 & 0.23 & 1.08 & 99.10 & & & & & & \\
\hline 12 & 0.08 & 0.38 & 99.48 & & & & & & \\
\hline 13 & 0.05 & 0.23 & 99.71 & & & & & & \\
\hline 14 & 0.03 & 0.12 & 99.83 & & & & & & \\
\hline 15 & 0.02 & 0.09 & 99.91 & & & & & & \\
\hline 16 & 0.01 & 0.04 & 99.96 & & & & & & \\
\hline 17 & 0 & 0.02 & 99.98 & & & & & & \\
\hline 18 & 0 & 0.01 & 99.99 & & & & & & \\
\hline 19 & 0 & 0.01 & 99.99 & & & & & & \\
\hline 20 & 0 & 0 & 99.99 & & & & & & \\
\hline 21 & 0 & 0 & 100.00 & & & & & & \\
\hline
\end{tabular}

Extraction Method: Principal Component Analysis.

In the column of the initial Eigenvalues, it illustrates the initial results that each variable contribute to the variable group. In the column of the Extraction Sums of Squared Loadings, it extracts the most significant six principal factors that are able to summarize the most information of the variable group. Only the factors whose initial eigenvalue is greater than 1 are extracted. In the column of the Rotation Sums of Squared Loadings, it demonstrates the results of rotated components (Through a component rotation, the relation between the original variables and the principal factors is rearranged to get the coefficient of factor loading more significant, thus get the principal factors outstanding. Meanwhile, the cumulative percents for each factor are changed, but the untimate sum $86.45 \%$ for all selected factors are unchanged after a rotation.).

The first column is the serial number of the variables. The second column is the eigenvalues assessing the variable significance. Those with eigenvalues beyond 1 are usually viewed as the principal factors.

The third column outlines the contribution rate $(C)$ of each varaible, denoted by $C=\lambda_{i} / \sum_{i=1}^{k} \lambda_{i}(i \leq k)$. The

fourth column shows their cumulative rate $\left(C_{c}\right)$, formulated by $C_{c}=\sum_{i=1}^{n} \lambda_{i} / \sum_{i=1}^{k} \lambda_{i}(n \leq k)$. For those selected principal factors, their cumulative contribution rate is required to be over $80 \%$, otherwise, they may not comprenhensively reflect the typical characteristics of the variable group.

The Table III demonstrates that a majority of variables can be replaced by the prior six principal factors that maintain $86.45 \%$ information of the variable group, The six extracted factors are essetial for addressing the research question, others could be omitted to avoid their disturbance to the further analysis. Particulary, the most significant one is the first factor, with 9.68 eigenvalue and $46.09 \%$ contribution. The differentials between these components are lively reflected by Fig. 1 .

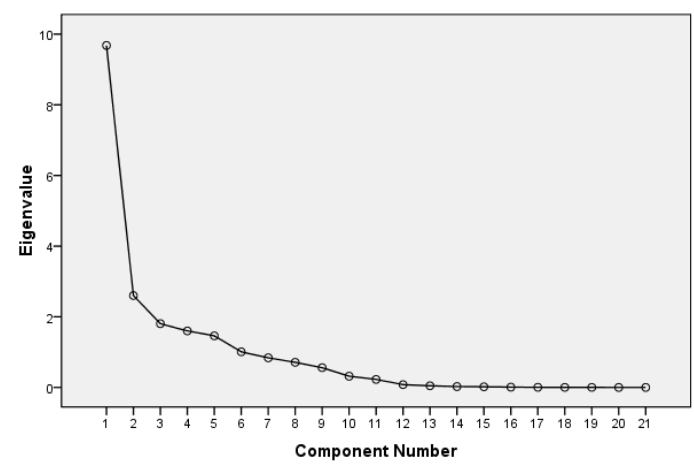

Fig. 1. Scree Plot.

This Fig. clearly outlines the distribution pattern of the factors' contribution rate. The differences of eigenvalue are very considerable between the first three factors, and then become gradual and flat eventually between the next ones. Therefore, the extracted six factors are able to influence the original variables significantly. Whereas, the rest factors have no remarkable contributions.

As Table IV indicated, the first principal factor $F_{1}$ has almost full factor loadings (0.937-0.995) on the firm-sized-related variables (NP, NA, IN), so the first principal factor is a firm-size determinant. The second factor $F_{2}$ remains dramatical loadings on variable $\mathrm{PR}_{2}$ 
(0.964) and $\mathrm{PR}_{1}(0.944)$, which means the second principal factor is a profitability-related determinant (NP). The third and fourth ones $\left(\mathrm{F}_{3}, \mathrm{~F}_{4}\right)$ are growth-rate-based determinants (GR), because they exert great impacts on $\mathrm{GRN}_{1}(0.822)$ and $\mathrm{GRI}_{1}(0.64)$, as well as $\mathrm{GRN}_{2}(0.902)$ and $\mathrm{GRI}_{2}(0.908)$ respectively. The fifth one $\left(\mathrm{F}_{5}\right)$ is clearely a share-specific determinant (IV), due to the striking loading coefficients, 0.881 and 0.836 for SAI and IV respectively. The last one is a return-level factor (DR) because of its strong association with the variable returns and return rate.

TABLE IV: ROTATED COMPONENT MATRIXA

\begin{tabular}{|c|c|c|c|c|c|c|}
\hline & \multicolumn{6}{|c|}{ Component } \\
\hline & $\mathrm{F}_{1}$ & $\mathrm{~F}_{2}$ & $\mathrm{~F}_{3}$ & $\mathrm{~F}_{4}$ & $\mathrm{~F}_{5}$ & $\mathrm{~F}_{6}$ \\
\hline $\mathrm{NP}_{1}$ & 0.995 & & & & & \\
\hline NA & 0.992 & & & & & \\
\hline $\mathrm{IN}_{1}$ & 0.990 & & & & & \\
\hline EPS & 0.987 & & & & & \\
\hline NS & 0.987 & & & & & \\
\hline $\mathrm{IN}_{2}$ & 0.983 & -0.129 & & & & \\
\hline $\mathrm{IN}_{3}$ & 0.983 & -0.128 & & & & \\
\hline $\mathrm{NP}_{2}$ & 0.981 & & & & 0.147 & \\
\hline DA & 0.938 & & & & & 0.271 \\
\hline $\mathrm{NP}_{3}$ & 0.937 & & & -0.143 & 0.186 & \\
\hline $\mathrm{PR}_{2}$ & & 0.964 & & 0.121 & & \\
\hline $\mathrm{PR}_{1}$ & & 0.944 & & & & \\
\hline $\mathrm{GRN}_{1}$ & 0.183 & -0.116 & 0.822 & & & -0.104 \\
\hline P.E. & -0.141 & & 0.698 & & 0.105 & 0.205 \\
\hline $\mathrm{GRI}_{1}$ & & 0.169 & 0.640 & 0.278 & -0.205 & \\
\hline ROE & & 0.234 & 0.422 & & & -0.332 \\
\hline $\mathrm{GRI}_{2}$ & & & & 0.908 & & \\
\hline $\mathrm{GRN}_{2}$ & & & & 0.902 & 0.116 & \\
\hline SAI & 0.101 & -0.103 & -0.196 & & 0.881 & \\
\hline IV & & 0.182 & 0.338 & & 0.836 & \\
\hline DR & & & & & & 0.929 \\
\hline
\end{tabular}

Extraction Method:Principal Component Analysis. Rotation Method: Varimax with Kaiser Normalization. a. Rotation converged in 5 iterations.

\section{RESULTS AND DISCUSSIONS}

In light of the empiricaly analysis, the most important IPO determinants are identified, which are firms size, profitability, growth rate, IPO volume, and dividend rate. This result demonstrates that the five factors are the key IPO determinants in the GEMC, so the issuer's performances in these respects are what the exchange concentrates on.

These findings are in line with those of prior studies. Pagano et al. [9] document that firm size as one of IPO determinants may be measured by a firm's sales income. My study finds that the net asset and net profit as proxies of firm size are the principal factors influcing IPOs in the emerging market. As Babich and Sobel [10] suggested, capital expenditures on assets are able to promote a growth in sales and profits, and consequently contribute to IPO probability.

In terms of profitability, firms with low profitability remain low probability of going public, due to the fact that they are unlikely to generate sufficient internal capital to return their investors [11]. Gao et al. [12] document that the profitability is a determinant of IPO probability for small firms. In addition, Fischer [13] suggests that the profitability including the net profit and its growth rate may affect IPO likelihood in many different ways. As such, the profitable firms are more prone to be listed [14] on share markets, because the high profitability could be a credible signal of IPO company, and thereby overcome adverse selection [15].

Going public to raise capital for the future growth overwhelmingly dominates the IPO motivations of listed firms on emerging share markets [16]. Growth opportunities is one of the determinants for IPO volume [1]. Consequently, the growth potential is one of the crucial factors of going public [11].

In terms of IPO volume, since the issuers with large IPO volume have lower risks than those with smaller offering size [17], IPO probability is positively related to the IPO volume [18]. Babich and Sobel [19] show that firms with large IPO volume are more likely survive longer after going public.

Regarding dividend rate, the long-term dividend returns are signals of an issuer's quality, because lower quality firms appear to have worse stock returns [20]. Pre-IPO return performance of a firm is basically able to reflect its post-IPO survival rate [16]. Particularly, firms with good return records are more likely to survive longer than others. Firth [21] demonstrates the three-year dividend returns after listing are positively related to the issuers' profitability.

\section{CONCLUSION}

This paper employing the PFA method investigates the key determinants for a successful IPO in the GEMC, and it suggests that a successful IPO application in the new listing market is mainly determinated by the five principal factors: firms size, profitability, growth rate, IPO volume, and dividend rate.

\section{REFERENCES}

[1] M. Lowry, "Why does IPO volume fluctuate so much?" Journal of Financial Economics, vol. 67, pp. 3-40, 2003.

[2] R. La Porta, F. Lopez-De-Silanes, A. Shleifer, and R. Vishny, "Law and finance," Journal of Political Economy, vol. 106, pp. 1113-1155, 1998.

[3] F. Bancel and U. R. Mittoo, "European managerial perceptions of the net benefits of foreign stock listings," European Financial Management, vol.7, no. 2, pp. 213-236, 2001.

[4] M. Pagano, A. Roell, and J. Zechner, "The geography of equity listing: why do companies list abroad?" The Journal of Finance, vol. 57, pp. 2651-2694, 2002.

[5] L. Hail and C. Leuz, "International differences in the cost of equity capital: do legal institutions and securities regulation matter?" Journal of Accounting Research, vol. 44, no. 3, pp. 485-531, 2006.

[6] Y. Chen and W. Wang, "On perfecting the credit guarantee system of China's SMEs," International Business Research, vol. 2, no. 3, pp. 132-135, 2009.

[7] X. Chen, X. Wang, and D. Wu, "Credit risk measurement and early warning of SMEs: An empirical study of listed SMEs in China," Decision Support System, vol. 49, pp. 301-310, 2010.

[8] Y. Cui, L. Zha, and F. Zhang, "Financial support system and strategy of SMEs in the incubation based on business life cycle," International Business Research, vol. 3, pp. 119-123, 2010.

[9] M. Pagano, F. Panetta and L. Zingales, "Why do companies go public? An empirical analysis," Journal of Finance, vol. 53, no. 1, pp. 27-64, 1998.

[10] V. Babich and M. J. Sobel, "Pre-IPO operational and financial decisions," Management Science, vol. 50, no. 7, pp. 935-948, 2004. 
[11] B. G. Albornoz and P. F. Pope, "The determinants of the going public decision: evidence from the UK," Working paper, Universitat Jaume I, Spain, 2004.

[12] X. Gao, J. R. Ritter and Z. Zhu, "Where have all the IPOs gone?" Working Paper, University of Hong Kong, University of Florida, The Chinese University of Hong Kong, 2012.

[13] C. Fischer, "Why do companies go public? Empirical evidence from Germany's Neuer Market," Working paper, Ludwig-Maximilians-Universitat Munchen, 2000.

[14] Y. P. Shen and P. Wei, "Why do companies choose to go IPOs? New results using data from Taiwan," Journal of Economics and Finance, vol. 31, no. 3, pp. 359-367, 2007.

[15] D. W. Diamond, "Monitoring and reputation: the Choice between bank loans and directly placed debt," Journal of Political Economy, vol. 99, pp. 689-721, 1991 .

[16] A. Singh, "Corporate financial pattern in industrializing economies: a comparative international study," International Financial Corporation Paper (No. 2), The World Bank, ISBN:0821332317, 1995.

[17] M. Levis, "The long-run performance of initial public offerings: the UK experience 1980-1988," Financial Management, vol. 22, pp. 28-41, 1993.

[18] B. Jain and O. Kini, "The life cycle of initial public offerings," Journal of Business Finance\& Accounting, vol. 26, pp. 1281-1307, 1999.
[19] M. Kooli and S. Meknassi, "The survival profile of US IPO issuers 1985-2005," The Journal of Wealth Management, vol. 10, pp.105-119, 2007.

[20] T. Loughran and J. R. Ritter, "The new issues puzzle," Journal of Finance, vol. 3, pp. 23-51, 1995.

[21] Firth M., "IPO profit forecasts and their role in signaling firm value and explaining post-listing returns," Applied Financial Economics, vol. 8, no. 1, pp. 29-39, 1998.

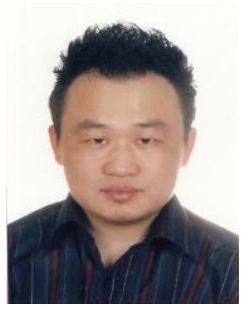

Hai Long was born in Huaibei, China in 1977. He received his bachelor in arts from Soochow University in 2001, and his Master in business administration from Hohai University, in 2009. He is expected to obtain his $\mathrm{PhD}$ in finance from Edith Cowan University, Australia, in 2014.

Prior to his academic career, he had 7-year working experience in industry. Currently, he is studying as a $\mathrm{PhD}$ candidate in school of business at Edith Cowan University, Australia. His research interest includes venture capital investment and IPO-related topics.

Mr. Long is a member of Australian Institute of Management, and a senior member of Society of Management Science of China. 